Политические проблемы международных отношений, глобального

и регионального развития

DOI: 10.31862/2500-2988-2020-11-2-106-118

\title{
А.А. Зыков
}

Дальневосточный федеральный университет, 690950 г. Владивосток, Российская Федерация

\section{Становление трансграничного сотрудничества России: дальневосточный аспект}

В статье освещается динамика освоения трансграничного формата сотрудничества в России и подключения ее Дальнего Востока к интенсивным связям с сопредельными странами Азиатско-Тихоокеанского региона. Трансформация конституционных основ российского государства конца XX в. сделала возможным взаимодействие акторов политических отношений сразу на двух уровнях: с иностранными и внутренними партнерами. Автор статьи анализирует динамику становления института трансграничного сотрудничества в контексте юридических и организационных основ государственно-политической системы России. Выделяет четыре этапа неравномерного процесса институционализации, соответствующие четырем периодам политического и социально-пространственного развития дальневосточного приграничного социума. Отечественная модель не получила пока завершающей устойчивой формы, но зато приобрела уникальные характеристики.

Ключевые слова: региональное развитие, Дальний Восток России, политические отношения, трансграничное сотрудничество, институционализация, дальневосточный приграничный социум 
ССЫЛКА НА СТАТЬЮ: Зыков А.А. Становление трансграничного сотрудничества России: дальневосточный аспект // Локус: люди, общество, культуры, смыслы. 2020. T. 11. № 2. С. 106-118. DOI: 10.31862/2500-2988-2020-11-2-106-118

\section{A.A. Zykov}

Far Eastern Federal University, Vladivostok, 690950, Russian Federation

\section{Formation of cross-border cooperation of Russia: The Far East aspect}

The article highlights the dynamics of the development of cross-border format of cooperation in Russia and the connection of its Far East to intensive relations with neighboring countries of the Asia-Pacific region. The transformation of the constitutional foundations of the Russian state at the end of the XX century made possible the interaction of actors of political relations at two levels: with foreign and domestic partners. The author of the article reconstructs the dynamics of the formation of the reference points of the metamorphosis of the system of public administration and political relations of different actors of cross-border cooperation in Russia. There are four stages of the uneven process of institutionalization, corresponding to the four periods of political and socio-spatial development of the Far Eastern border society. The domestic model has not yet received the final stable form, but it has acquired its unique characteristics.

Key words: regional development, the Far East of Russia, political relations, crossborder cooperation, institutionalization of the trans-frontier cooperation, Far Eastern border society

CITATION: Zykov A.A. Formation of cross-border cooperation of Russia: The Far East aspect. Locus: People, Society, Cultures, Meanings. 2020. Vol. 11. No. 2. Pp. 106-118. (In Russ.) DOI: 10.31862/2500-2988-2020-11-2-106-118 
Конец первого десятилетия XXI в. обозначился новым витком глобальной трансформации мировой системы. Глобальный экономический кризис 2008 г. повлек за собой обострение противоречий постсоветского миропорядка. Новые процессы и порождаемые ими проблемы, частью имевшие зарубежные истоки, но в большинстве случаев отягощавшиеся общей отечественной и региональной спецификой, обусловили актуальность исследования институционализации трансграничного формата сотрудничества в системе политических отношений Дальнего Востока России.

Цель статьи заключается в анализе роли трансграничного сотрудничества в развитии отношений между властными структурами различного уровня и другими акторами, стремившимися стать субъектами политического процесса в регионе.

Регионализм как процесс расширения экономического и, как следствие, политического влияния регионов внутри страны и за пределами территории суверенного государства получил мощный импульс развития еще в 1980-е гг. [7]. Активное развитие межгосударственного сотрудничества на региональном уровне в этот период превосходило своими масштабами и динамикой предшествующий мировой опыт, хотя в последующей практике прослеживаются периоды снижения интенсивности, обусловленные различными причинами.

Понятие «регион» является наиболее функциональным в процессе описания исследуемого феномена и охватывает различные его составляющие. Регионом допустимо называть и Северо-Восточную Азию, и Дальний Восток России, и Хабаровский край или любой другой субъект федерации. В составе Приморского края выделяются муниципальные районы, которые в свою очередь могут делиться по географическому признаку, например, северные территории; с точки зрения экономистов и географов их тоже допустимо называть регионами или собственно районами. Регион как пространственно-территориальная целостность, сопряженная с экономической, политической и социокультурной системой, выделяется по критерию научного интереса исследователя.

В целях систематизации применения термина «регион» определим иерархию данных территориальных объектов. По мнению Р.Ф. Туровского, структура соподчиненности территориально-политических таксономических категорий подразделяется на глобальный (макроуровень), национальный (мезоуровень), субнациональный и локальные (микро-) уровни [9, с. 33-34].

Россия своими дальневосточными территориями соприкасается с международным регионом Северо-Восточная Азия (и США), который скреплен географическим, геополитическим и геоэкономическим факторами. 
На национальном (государственном) уровне Дальний Восток России относится к административно-хозяйственному образованию, имеющему собственные государственные органы управления (например, Восточный военный округ и структуры, представляющие федеральную власть) и относительно развитые объекты народного хозяйства. Однако это территориальное образование не имеет собственной политической субъектности, определяемой наличием единого бюджета, законодательных и других эффективных институтов. Дальний Восток представляет собой скорее площадку для апробации федеральных проектов территориального развития и налаживания межрегиональных связей различных субъектов, чем единую социально-экономическую систему.

Исходя из российской специфики функционирования государственно-политической системы, с характерной для нее концентрацией публичных полномочий на уровне субнациональных политических структур, в узком, функциональном смысле регион в Российской Федерации - это административная единица территориального устройства государства, называемая субъектом федерации. Руководство субнациональных регионов (главы субъектов РФ и их команды - региональная власть) является активным участником федеративных отношений и неотъемлемой составляющей местных политических элит, выполняющих роль проводников в региональном политическом и социально-экономическом процессах развития. По наблюдению А.Н. Горской, губернаторский корпус занимает особое место, т.к. участие представителей региональных и местных элит ввиду их политической и экономической заинтересованности прямо или косвенно сказывается на успехе трансграничного сотрудничества [2, с. 114].

Несмотря на то, что регионализм - в первую очередь в своей экономической ипостаси - получил широкое распространение в Азиатско-Тихоокеанском регионе, западный опыт был определяющим в понимании и проектировании международных региональных объединений и трансграничного сотрудничества. Принятие в 1980 г. в Мадриде «Европейской рамочной конвенции о трансграничном сотрудничестве между территориальными сообществами или местными властями» (далее Мадридская конвенция) является ключевым моментом институционализации трансграничного сотрудничества [10]. Конвенция определила административный статус новой формы сотрудничества, пространство распространения которой характеризуется социально-экономической, политической и социокультурной общностью. Впервые территориальные сообщества получили возможность инициативы международной кооперации, что дает нам возможность понимать под трансграничным сотрудничеством систему отношений разновеликих политических 
акторов в процессе формирования общего интеграционного пространства с соседними странами.

Заимствование европейского опыта позитивно оценивали некоторые исследователи восточноазиатской интеграции, в его развитии видели залог мирного сосуществования и возможности развития периферийных регионов во многих отраслях жизнедеятельности [11; 12].

Динамика подключения Дальнего Востока России к интенсивным трансграничным связям Азиатско-Тихоокеанского региона по форме и масштабам была неравномерной. В целом, можно выделить четыре этапа институционализации трансграничного сотрудничества в России, соответствующие четырем периодам политического и социально-пространственного развития дальневосточного приграничного социума: 1992-1999 гг. - фрагментации, 1999-2006 гг. - адаптации, 2006-2012 гг. консолидации, 2012 г. - по настоящее время - «национализации».

\section{Открытие регионов и прозрачные границы}

Россия на первом этапе становления нового федерализма с неограниченным союзным уровнем власти суверенитетом регионов получила разбалансированный аппарат государственных органов управления, всеобъемлющий социально-экономический кризис, открытые границы и рвущиеся реализовать свои федеральные и международные амбиции региональные элиты. В прошлом дальневосточные приграничные контакты СССР носили ограниченный характер и имели строго контролируемый государственными и партийными органами принцип организации. Так, объемы прибрежной торговли с Японией были весьма скромными. Корейская Народно-Демократическая Республика (КНДР) в ответ на многолетние вливания СССР в экономику дружественного режима поставляла продовольствие и товары легкой промышленности в Приморский край. Мероприятия в культурной, научной и других областях взаимоотношений с КНДР, сама деятельность Общества советско-корейской дружбы, были порой формальными по своему характеру, детально контролировались с обеих сторон. Отношения с Китаем в 1960-1980-е гг. были напряженными.

Усиление центробежных тенденций в 1990-е гг. на этапе стихийной федерализации сыграло неоднозначную роль в развитии системы государственного управления. На основе союзного договора (март 1992 г.) и новой Конституции России (декабрь 1993 г.) произошла децентрализация государственного управления и расширение полномочий субъектов федерации [1, с. 183]. Было конституционно закреплено за субъектами РФ право международной деятельности, получила развитие частная приграничная торговля. 
После крушения советских экономических связей с центральными районами России и бывшими республиками СССР жители Дальнего Востока восполняли свои нужды за счет наращивания приграничной торговли с Китаем. Приграничье испытало всплеск миграционной активности. Ранее закрытая внутренняя территория военно-стратегического назначения с господством военно-промышленной компоненты в структуре хозяйствования стала динамично осваивать возможности внешнеэкономической деятельности. «Челночная торговля» товарами широкого потребления из приграничных городов Китая, импорт подержанных автомобилей из Японии стали существенным сектором экономики и зачастую единственной стратегией выживания для местного населения.

Региональные власти принимали активное участие в институционализации трансграничной системы Северо-Восточной Азии (СВА), взаимодействии субнациональных администраций. Так, была образована группа взаимодействия в зоне Японского моря. В эту группу вошли Приморский и Хабаровский края, японские префектуры Ниигата, Тоттори и Тояма, китайские провинции Цзилинь и Хэйлунцзян, южнокорейские провинции Канвон, Северный и Южный Кёнсан. В 1996 г. на ее основе была создана Ассоциация региональных (субнациональных) администраций стран СВА - AРАCСВА [7, с. 110].

Во второй половине 1990-х гг. произошло значительное упорядочение трансграничной деятельности регионов как за счет координационных структур (Департамент по связям с субъектами РФ в составе МИД РФ, Консультативный совет субъектов РФ по международным и внешнеэкономическим связям при МИД РФ), так и за счет усиления правовой базы (были приняты федеральные законы о международных договорах, основах государственного регулирования внешнеторговой деятельности и др.).

\section{Адаптация к условиям мирового развития}

На втором этапе принимается основная общероссийская и региональная нормативная база, регулирующая международную и внешнеэкономическую деятельность субъектов РФ. Постепенно ограничивается мелкая и средняя приграничная торговля, разрабатываются планы переориентации приграничной инфраструктуры с военного на социально-экономическое назначение. На рубеже XX-XXI вв. в обществе и элите оформился запрос на политику консолидации государства и восстановление его административного потенциала, снижение дифференциации и фрагментации форм управления общественными отношениями. В структуре государственных институтов появляются органы, 
координирующие трансграничную деятельность субнациональных акторов и региональное развитие. Органы, обеспечивающие пограничный режим и таможенный контроль, разрабатывают новый подход обеспечения своих функций в условиях открытой границы.

Федеральным законом «О координации международных и внешнеэкономических связей субъектов РФ» трансграничная деятельность регионов была введена в строгие конституционные рамки, четко прописано распределение полномочий. Главным образом, были исключены сепаратистские устремления регионов политического и военно-политического характера, актуальные для расползающейся федерации 1990х гг. В остальном закон разрешил местным властям устанавливать все виды международных связей. Согласно принятым нормативным положениям, региональная власть обладала достаточными полномочиями, но, с точки зрения представительства интересов местного сообщества, вопрос был открыт.

По мнению экспертов, трансграничная деятельность муниципалитетов не получила необходимого политико-правового статуса [4; 8]. В 1998 г. были ратифицированы Европейская хартия о местном самоуправлении, в 2003 г. - Мадридская конвенция. Но на проект закона о координации международных связей субъектов РФ и муниципальных образований РФ было дано отрицательное заключение Министерства юстиции РФ. Это можно объяснить политическими факторами, заключающимися в недостаточном теоретическом осмыслении приграничного сотрудничества и перегруженности системы государственного управления длительными политико-экономическими реформами. Органы государственной власти стали настаивать на самодостаточности действующего законодательства.

С конца 1990-х гг. наметился отчетливый уклон в сторону секьюритизации и укрепления рубежей с соседними странами. Тенденция ужесточения пограничной политики РФ, в силу обострения Чеченского конфликта и угроз терроризма, была во многом вынужденная, затронув почти весь периметр государственной границы. Темпы модернизации приграничной инфраструктуры были недостаточны, предложения от силовых структур о закрытии ряда пунктов пропуска на границе стали звучать все чаще.

Осознание необходимости соблюдения оптимального баланса между политикой российского государства, направленной на развитие международных контактов с соседями, и защитой национальных интересов, пришло только недавно. Навести порядок, предотвратить конкуренцию между центрами власти призван был институт полномочного представителя президента в Дальневосточном федеральном округе (ДФО), 
созданный в 2000 г. наряду с другими шестью округами и их кураторами. Границы ДФО совпали с Восточным военным округом. Это свидетельствует об обозначении приоритета вопросов безопасности на предстоящем этапе государственного строительства, повышении значимости силовых структур в вопросах не только стратегического, но и социальноэкономического характера.

Перед полпредом стояла задача привести региональное нормотворчество в соответствие с федеральным законодательством. Высокое положение полпреда в вертикали российской власти, прямая связь с высшим руководством страны позволяли ему проводить встречи с региональными властями и с представителями высшего руководства соседних стран, курировать наиболее серьезные вопросы взаимодействия с соседними государствами. Также он выступал в роли посредника в случае возникновения споров между Москвой и регионами, совместно с Межрегиональной ассоциацией экономического взаимодействия «Дальний Восток и Забайкалье» способствовал формированию социально-экономической программы развития регионов. При полпреде образовались различные структуры, координационные советы и комиссии, объединяющие руководителей исполнительных органов власти, региональных и местных политиков и предпринимателей, в т.ч. по вопросам функционирования границы.

В послании Федеральному собранию РФ в мае 2003 г. президент В.В. Путин отметил тесную связь экономических и социальных проблем с неэффективностью политической системы: «До сих пор не удается создать устойчивую политическую модель, которая справлялась бы и с задачей развития страны, интеграции ее в мировые процессы» [5]. Осенью 2004 г. были отменены прямые выборы глав субъектов РФ, что повысило значение полпреда в жизни регионов.

\section{Консолидация сил перед прорывом}

Третий этап отличался консолидацией сил государства, повышением роли федерального центра и декларировался как переходный к новому уровню развития сотрудничества, направленного на социально-экономическое развитие Дальнего Востока и повышение роли России в СВА. Реализуются крупные проекты, курируемые федеральным правительством (нефтепроводная система «Восточная Сибирь - Тихий океан», саммит АТЭС во Владивостоке в 2012 г. и т.д.). Только к середине первого десятилетия 2000-х гг. были приняты масштабные планы модернизации приграничной инфраструктуры, к этому времени состояние многих пропускных пунктов и мостовых переходов было плачевным [3]. 
Особенности развития системы политических отношений и государственного управления России в 2006-2012 гг. привели к кардинальному изменению структуры региональной политики на Дальнем Востоке и соответствующего сектора трансграничного сотрудничества. Учитывая намерение использовать взаимодействие с азиатскими соседями как рычаг развития всей страны, вполне закономерно был сделан вывод, что экономический прорыв в условиях остроконкурентной среды АТР требует консолидации значительных ресурсов страны. Только государство (в лице федерального руководства) способно мобилизовать соответствующую финансово-организационную поддержку дальневосточным регионам для завоевания достойного места в Азиатско-Тихоокеанской трансграничной региональной системе отношений.

К тому же в это время страна подошла к активной фазе присоединения к Всемирной торговой организации (ВТО). В ходе переговорного процесса по присоединению к ВТО постепенно принимались нормативные акты, совершенствовалось законодательство России. Осложнил этот процесс в 2008 г. мировой финансовый кризис, заставивший множество стран задуматься о регулировании национальных экономик посредством протекционистских мер. Еще до проведения саммита АТЭС во Владивостоке в 2012 г. В.В. Путин подписал закон о присоединении к ВТО.

Несмотря на консолидацию всех ресурсов в руках федеральной власти, региональные акторы еще выполняли важную роль в региональном развитии. Да и федеральную власть на Дальнем Востоке в качестве полномочного представителя Президента РФ в ДФО с 2009 по 2012 гг. представлял многолетний губернатор Хабаровского края В.И. Ишаев.

\section{«Национализация» импортируемых институтов или закрепление отечественной специфики трансграничности}

С 2012 г. курс на углубление интеграции в АТР приобрел планомерность, в мае было образовано Министерство РФ по развитию Дальнего Востока (Минвостокразвития). Инструменты, предложенные министерством, легли в основу федеральных целевых программ социальноэкономического развития дальневосточных территорий, механизмов территорий опережающего развития и Свободного порта, организации ежегодных Восточных экономических форумов и других инициатив. В 2015 г. была принята концепция развития приграничных территорий ДФО, которая не способствовала развитию новых форм сотрудничества, зато признала плачевное состояние инфраструктуры и социально- 
экономической ситуации депрессивных поселений этих пространств. Объекты опеки и декларированного развития выделялись сугубо по географическому критерию: территории муниципальных образований ДФО, прилегающие к государственной границе РФ с КНР и КНДР [6].

К сожалению, богатейшие территории остаются на периферии интеграции в СВА. Мультипликативный эффект от выполнения Дальним Востоком роли ключевого звена в трансграничной политике России до сих пор не сработал. Реализация продвигаемых мегапроектов территорий опережающего развития и т.п. предполагает существенное увеличение инвестиций. Это обстоятельство дает основание для вывода о незавершенности данного этапа институционализации.

С другой стороны, летом 2017 г. произошло долгожданное принятие федерального закона о приграничном сотрудничестве. Закон предоставил широкие полномочия органам местного самоуправления. Окна возможностей открылись для всех муниципалитетов в составе приграничного региона, а не только для тех, которые примыкают к государственной границе.

Реализованный подход развивает международные связи приграничных муниципальных образований в рамках внешних взаимоотношений РФ. Основной партнер этих отношений - это сопредельный муниципалитет соседней страны. В целом, на органах местного самоуправления лежит непосредственное обеспечение жизнедеятельности населения, посильное содействие подготовке на своей территории международных мероприятий, инициируемых региональной и федеральной властями. Однако большинство дальневосточных приграничных муниципалитетов не имеют достаточной материально-финансовой базы. До широты спектра возможностей европейских местных сообществ нашим муниципалам еще далеко.

\section{Заключение}

Пройден путь от стихийного освоения трансграничных практик, увлечения западным опытом и мировыми стандартами к планомерному курсу упорядочивания трансграничных контактов и согласования региональных инициатив с внешнеполитической траекторией федерального центра с целью концентрации национального потенциала в новых условиях международного контекста. Несмотря на глобальные тренды и мировые трансформации, государство и национальные правительства остаются основными политическими акторами, что четко видно из проведенного обзора российской динамики становления трансграничного сотрудничества как относительно новой сферы деятельности. 
В 2010-х гг. произошла условная «национализация» импортируемых институтов, универсалии и мировые стандарты преломили сквозь призму отечественного опыта и местных условий, законодательные инициативы закрепили существующее положение вещей.

Влияние процессов регионализации и глобализации постепенно взяли под контроль, определив приоритет безопасности над трансграничным сотрудничеством. Этому обстоятельству немало способствовало осложнение отношений со странами Запада, введение ограничительных мер со стороны США и их союзников. Международно-политический порядок нестабилен. Федеральное руководство и иные акторы политико-экономического процесса не рассчитывали на закрепление сложившейся ситуации. Более того, были предприняты активные действия по развитию альтернативных направлений трансграничного сотрудничества, в первую очередь, «восточный поворот» к Китаю и азиатским экономикам. Таким образом, происходит поиск оптимального соотношения между заинтересованностью как федерального центра, так и регионов в интенсивных международных (в т.ч. транснациональных) связях и необходимостью в защите национальных интересов. Обеспечение баланса требует постоянного внимания и новых решений. Отечественная модель трансграничного сотрудничества на данном этапе не является стабильной. Как сложная и многоуровневая система, она определяется характером международных отношений и параметрами эволюции российской политической системы, расширяющими или сужающими возможности трансграничного сотрудничества.

\section{Библиографический список / References}

1. Вардомский Л.Б. Российское порубежье в условиях глобализации. М., 2009. [Vardomskiy L.B. Rossiyskoe porubeze v usloviyah globalizacii [Russian felling in the context of globalization]. Moscow, 2009.]

2. Горская А.Н. Трансграничное сотрудничество Псковской области и Республики Беларусь // Локус: люди, общество, культуры, смыслы. 2019. № 4. C. 112-122. [Gorskaya A.N. Cross-border cooperation of the Pskov region and the Republic of Belarus. Locus: People, Society, Cultures, Meanings. 2019. No. 4. Pp. 112-122). (In Russ.)]

3. Межрегиональное и приграничное сотрудничество государств - участников СНГ: проблемы и перспективы: информационно-аналитический доклад Исполнительного комитета. М., 2006. [Mezregionalnoe i prigranichnoe sotrudnichestvo gosudarstv - uchastnikov SNG: informatsionno-analiticheskiy doklad Ispolnitelnogo komiteta [Interregional and cross-border cooperation of the CIS member States: Problems and prospects: Information and analytical report of the CIS Executive Committee]. Moscow, 2006.] 
4. Мирошников С.Н. О проекте закона о координации международных связей субъектов Российской Федерации и муниципальных образований // Международные и внешнеэкономические связи субъектов Российской Федерации. Оренбург, 2004. С. 43-52. [Miroshnichenko S.N. On the draft law on the coordination of international relations of the constituent entities of the Russian Federation and municipalities. Mezdunarodnye $i$ vneshneeconomicheskie svyazi subektov Rossiyskoy Federacii. Orenburg, 2004. Pp. 43-52. (In Russ.)]

5. Послание Федеральному Собранию Российской Федерации 16 мая 2003 года// Официальный сайт Президента РФ Kremlin.Ru. URL: http://www. kremlin.ru/events/president/transcripts/21998 (дата обращения: 12.08.2015). [Message to the Federal Assembly of the Russian Federation on 16 may 2003. URL: http://www.kremlin.ru/events/president/transcripts/21998. (In Russ.)]

6. Распоряжение Правительства РФ № 2193-р от 28 октября 2015 г. «Об утверждении концепции развития приграничных территорий субъектов Федерации Дальневосточного федерального округа» // Официальный сайт Правительства РФ. URL: http://government.ru/docs/20380/ (дата обращения: 12.08.2019). [Rasporyagenie pravitelstva RF no.2193-r ot 28 oktyabrya 2015 g. «Ob utvergdenii koncepcii razvitiya prigranichnyh territoriy cub'ektov Federacii Dalnevostochnogo federalnogo okruga [Order of the Government of the Russian Federation No. 2193-R of October 28, 2015 "On approval of the concept of development of the border territories of the far Eastern Federal district']. URL: http://government.ru/docs/20380/]

7. Севастьянов С.В. Неправительственные участники сотрудничества Восточной Азии: вклад в развитие регионализации и региональной идентичности. Владивосток, 2009. [Sevastyanov S. Nepravitelstvennye uchastniki sotrudnichestva Vostochnoy Azii: vklad v razvitie regionalizacii i regionalnoy identichnosti [Non-governmental participants in East Asian cooperation: Contribution to the development of regionalization and regional identity]. Vladivostok, 2009.]

8. Семакина Ю.А. Приграничное сотрудничество муниципальных образований (муниципально-правовое исследование): Автореф. дис. ... канд. юрид. наук. M., 2014. [Semakina Yu.A. Prigranichnoe sotrudnichestvo municipalnuh obrazovaniy (municipalno-pravovoe issledovanie) [Cross-border cooperation of municipalities (municipal legal research]. PhD thesis. Moscow, 2014.]

9. Туровский Р.Ф. Политическая регионалистика. М., 2006. [Turovskiy R.P. Politicheskaya regionalistika [Political regionalism]. Moscow, 2006.]

10. European outline convention on trans-frontier cooperation between territorial communities or authorities. Madrid, 24.05.1980. European Treaty Series. No. 106. URL: https://rm.coe.int/1680078b0b (accessede: 03.12.2019).

11. Lay Hwee Yeo. Institutional regionalism versus networked regionalism: Europe and Asia compared. International Politics. 2010. Vol. 47. No. 3/4. Pp. 324-337.

12. Tetsu Sadomoto. Cooperation for peace and development in Northeast Asia: Functionalist approaches. The Iinternational Journal of Peace Studies. 1996. No. 2. Pp. 75-83. 
Сведения об авторе / About the author

Зыков Александр Александрович - соискатель кафедры международных отношений Восточного института - Школы международных и региональных исследований, Дальневосточный федеральный университет, г. Владивосток

Alexander A. Zykov - applicant at the International Relation Department of the Institute of Oriental Studies - School of Regional and International Studies, Far Eastern Federal University

E-mail: sunych_84@mail.ru 